ISSN: $1130-2887$

\title{
EMPRESARIADO, ESTADO Y POLÍTICAS PÚBLICAS EN BRASIL: NUEVAS TENDENCIAS EN EL UMBRAL DEL NUEVO MILENIO
}

\author{
Business, State and Public Policies in Brazil: New trends \\ at the dawn of a new Millennium
}

\author{
Eli DiNIZ \\ Instituto de Economía de la UFRJ-IUPERS, Brasil \\ - dinizeli@terra.com.br
}

BIBLID [1130-2887 (2003) 33, 125-156]

Fecha de recepción: noviembre del 2002

Fecha de aceptación y versión final: febrero del 2003

RESUMEN: El artículo evalúa el alcance y la profundidad de las transformaciones desencadenadas en Brasil a partir de la década de los años 80, cuando la instauración de la democracia y la ejecución de las reformas orientadas al mercado asumen el primer plano de la agenda pública. Mediante un contraste entre las décadas de los 80 y 90, este trabajo enfatiza los cambios en el orden económico y en la organización social del país, destancando las modificaciones de naturaleza política e institucional. Y para ello analiza particularmente el estilo de gestión pública, la naturaleza del proceso de toma de decisiones, las formas de articulación entre Estado y sociedad, así como los canales de acceso a los centros de decisión. Por último, se abordan las transformaciones en el peso relativo y en el papel de los actores estratégicos del nuevo orden capitalista en construcción.

Palabras clave: Brasil, empresariado, políticas públicas, Estado, democracia.

ABSTRACT: The article examines the scope and depth of the changes in Brazil since the 1980s, when the transition to democracy and the implementation of market reforms came to the forefront of the public agenda. Through a comparison between the 1980s and 1990s, the article examines developments in the economic order and social structure of Brazil with particular emphasis on political and institutional changes. With this aim, the paper looks specifically at the style of public management, the nature of the decision-making process, and the channels of statesociety interaction as well as the mechanisms for access to the decision-making centres. Finally, the article assesses the changes and relative importance of strategic actors in the new capitalist order.

Key words: Brazil, business sector, public policy, State, democracy. 


\section{INTRODUCCIÓN* **}

Las dos últimas décadas del siglo veinte representaron momentos decisivos en la trayectoria de la sociedad brasileña. Sucesivas crisis internacionales y el avance del proceso de globalización produjeron presiones que se tradujeron en una drástica redefinición de la agenda pública, especialmente en lo referido a las características políticas y económicas del país. Democratización, programas de estabilización económica, reformas orientadas al mercado, integración en el orden internacional globalizado se convirtieron en las nuevas prioridades, traduciéndose en una reorientación de las políticas públicas que serían puestas en práctica por los gobiernos del periodo post-autoritario. Se observó una intensa producción legislativa y reguladora, además de una no menos intensa actividad centrada en la consecución de la pauta de reformas. En consecuencia, se verificaron cambios profundos que no sólo afectaron al régimen político en vigor, sino también al modelo económico, el tipo de capitalismo, la modalidad de Estado, las características del sistema político y las relaciones Estado-sociedad.

El alcance de estos cambios no puede, por lo tanto, ser subestimado. Respecto a este punto se observa cierto consenso. Por otro lado, persisten algunos equívocos en lo que concierne a la génesis y la forma de conducción de este conjunto de transformaciones. En este aspecto, cabe resaltar la visión de que expresarían el resultado inexorable del proceso de globalización. La lógica ineluctable del nuevo orden mundial impondría una reorientación, según un recetario único, no existiendo otra alternativa que el ajuste a las nuevas condiciones. Esta interpretación oscurece la relevancia de la dimensión política. Al contrario de lo que afirma el enfoque determinista, no estamos ante un proceso espontáneo o automático de cambio. Las restricciones externas y la presión de agencias multilaterales como el FMI y el Banco Mundial, ejercieron una fuerte influencia en la determinación de las nuevas agendas, pero no de una forma mecánica e inmediata. Las opciones de las elites dirigentes nacionales, las características de sus coaliciones de apoyo político, o la acción deliberada en pos de la consecución de determinados objetivos son aspectos no menos decisivos en la definición de las políticas efectivamente implementadas y en la elección de la forma de inserción en el sistema internacional.

De forma similar, la secuencia, el ritmo y el contenido de los cambios sufren variaciones significativas, que no son dictadas por criterios exclusivamente técnicos, sino que reflejan decisiones de naturaleza política. Una vez más, el predominio de los enfoques que privilegian la variable económica ocultan o tienden a minimizar el significado de estas diferencias. De esta forma, las décadas de los 80 y 90 son con frecuencia

* $\quad$ Este texto, en su primera versión, fue presentado en el Seminário Internacional de Ciência Política, realizado en Porto Alegre, el día 5/10/2001, promovido por el PPGCP/UFRGS y la Associação Universitária do Grupo de Montevidéu. Agradezco a los organizadores del evento, principalmente a los profesores Céli Pinto y André Marenco, la invitación para participar en la mesa Gobierno y Políticas Públicas.

** Traducción de Carlos Muñoz Gallego, periodista y profesor de la Casa de España de Rio de Janeiro. 
tratadas indistintamente, enfatizándose unilateralmente los puntos de continuidad. Efectivamente estas dos décadas tienen un punto en común: el hecho de haber constituido el marco de la ruptura del pacto de poder que, durante 50 años (entre 1930 y 1970), sustentó la industrialización por sustitución de importaciones. El agravamiento de las restricciones externas y el refuerzo de las «condicionalidades» impuestas por las agencias multilaterales de desarrollo al reducir el grado de libertad de los gobiernos nacionales, llevaron a poner el énfasis en la administración de la crisis macroeconómica y la sustitución de metas como la industrialización y el planeamiento económico por políticas de estabilización y ajuste fiscal. Entre tanto, en el caso de Brasil, considerando los aspectos antes destacados, se hace posible comprender los contrastes entre aquellas dos décadas. De este modo, los puntos de ruptura adquieren nitidez, sobresaliendo los años 90 como un punto de inflexión en la trayectoria reciente del capitalismo brasileño.

Teniendo en cuenta estas consideraciones, el presente trabajo pretende evaluar el alcance y la profundidad de los cambios desencadenados en Brasil a partir de la mitad de los años 80, cuando la instauración de la democracia y la ejecución de las reformas orientadas al mercado asumen el primer plano de la agenda pública. Enfocando el contraste entre las décadas de los 80 y 90, se dará énfasis a las transformaciones en el orden económico y en la organización social del país, destacándose los cambios de naturaleza política e institucional. Entre éstos, se examinarán particularmente el estilo de gestión pública, la naturaleza del proceso de toma de decisiones, las formas de articulación entre Estado y sociedad, así como los canales de acceso a los centros de decisión. Por último, serán abordadas las transformaciones en el peso relativo y en el papel de los actores estratégicos del nuevo orden capitalista en construcción.

\section{LOS AÑOS 90 Y EL AHONDAMIENTO DEL CORTE CON EL PASADO}

Un primer contraste observable se refiere a las prioridades, la amplitud y el abarque de la agenda pública. A partir de la segunda mitad de los años 80 , la agenda tendrá como prioridad la instauración de la democracia y la ruptura con el legado del régimen autoritario. Este primer momento de retorno a la democracia corresponde con el gobierno del presidente José Sarney (1985-1989), que sube al poder basándose en una coalición bastante heterogénea y diferenciada internamente, expresión del amplio abanico de fuerzas políticas que lideró la transición del régimen militar al gobierno civil. Como es sabido, la transición brasileña se caracterizó por su gradualismo, siendo fruto de una amplia negociación que incluía sectores ligados al régimen militar junto con segmentos de oposición, en este proceso de instauración del nuevo orden. La tensión entre continuidad y cambio marcó todo el largo recorrido en dirección a la implantación de la democracia.

Si por un lado el tema de las reformas políticas fue consensual, por otro lado, en aquel momento todavía no existía consenso, ni dentro de la coalición política dominante, ni en el interior del equipo gubernamental sobre las directrices que deberían nortear 
el desarrollo del capitalismo brasileño una vez superada la crisis. De la compleja red de alianzas sobre la que se sustentaba el gobierno de José Sarney, formaban parte liderazgos de diferentes matices ideológicos, incluyendo posiciones identificadas con valores dispares, contraponiendo nacionalistas e internacionalistas, liberales y antiliberales, «privatistas»y «estatalistas». Entre los adversarios del liberalismo, algunos defendían un proyecto de fortalecimiento económico basado en la industrialización, bajo la dirección de un Estado todavía muy intervensionista. El compromiso con la meta de conciliar crecimiento económico con el combate contra la pobreza y la desigualdad social era hegemónico entre las principales fuerzas políticas que comandaron la transición democrática. En consecuencia, se formuló una agenda de amplio alcance, incluyendo entre sus prioridades, además del control de la inflación y del déficit fiscal, el llamado rescate de la deuda social. El alto grado de disenso entre las elites dirigentes acentuó los conflictos alrededor de las prioridades económicas y sociales.

En términos más específicos, prevalecía un amplio desacuerdo respecto al agotamiento del antiguo modelo de desarrollo, ya fuera en sus aspectos económicos, o en sus soportes institucionales. Existía todavía una apuesta en las potencialidades de aquel modelo, aceptándose, en gran medida, la idea de que, mediante algunas políticas de reforma, sería posible eliminar las distorsiones que lo habían desfigurado a lo largo del tiempo. En síntesis, el modelo aún no estaba desacreditado. En el debate político, soberanía y proyecto nacional eran temas valorizados, las empresas estatales no eran observadas como sobrevivientes de un pasado a ser enterrado y, por último, todavía se admitía la pertinencia de la política industrial como importante instrumento de política económica.

Es cierto que la matriz estadocéntrica estaba sufriendo un proceso de desgaste lento y gradual desde mediados de los años 70 , como consecuencia de las profundas transformaciones desencadenadas por el proyecto desarrollista puesto en práctica por la dictadura militar, cuyo éxito llevó al declive de la ordem regulada (Santos, 1985) y al desarrollo de una sociedad compleja y diferenciada. Con el paso del tiempo, se multiplicaron las evidencias de la corrosión de los rasgos distintivos del antiguo orden. Mientras tanto, la desarticulación de esta matriz aún no se constituyó en objeto de una política deliberada del gobierno, en su cualidad de condición necesaria para el ingreso en una nueva fase.

En este contexto de tensa convivencia entre continuidad y cambio se elaboró la Constitución de 1988. La llamada Constitución ciudadana dio origen a una amplia movilización política, marcada por una intensa participación de la sociedad civil, a través de sus diferentes segmentos. Expresando la heterogeneidad de la correlación de fuerzas típica de aquel momento, en que todavía no se había constituido un nuevo pacto de dominación, la nueva Carta tenía un contenido híbrido, encerrando innumerables dispositivos que reforzaban el legado del antiguo modelo, especialmente en lo que se refiere a la distinción entre empresas nacionales y extranjeras, papel del capital externo, monopolio estatal de recursos minerales estratégicos, así como varios aspectos de la legislación sindical y laboral. Estableciendo un plazo de cinco años para la revisión de sus aspectos más controvertidos, por medio de enmiendas constitucionales, los 
propios constituyentes parecían reconocer el carácter transitorio del acuerdo que había hecho posible la elaboración de la nueva Constitución.

Fue solamente con la ascensión de Fernando Collor a la Presidencia de la República que la meta del desmantelamiento del legado del pasado se volvería prioritaria, asumiendo el primer plano de la agenda pública, ya en el umbral de los años 90. Junto con el lema de la guerra a los marajás y la redención de los descamisados, el entonces candidato anti-establishment estigmatizaría al capitalismo autárquico brasileño, apuntando su principal fallo, el generar una industria artificial, ineficaz e incluso anticuada, incapaz por tanto de competir en un mercado internacional cada vez más exigente en términos de calidad y sofisticación tecnológicas. Esta visión sería resumida en la frase que al condenar a la industria automovilística, buque insignia del modelo de industrialización brasileño, por producir carromatos en lugar de automóviles de última generación, proyectó este segmento empresarial como el símbolo del atraso de la industria nacional.

En el transcurso de la década de los 90, en contraposición con los años 80, se radicaliza el corte con el pasado, a través de la articulación de una nueva y amplia coalición política, que se convirtió en victoriosa con la elección en 1994 del presidente Fernando Henrique Cardoso. En este momento se observa de forma simultánea la disgregación de la coalición desarrollista. A partir de entonces, se redefine drásticamente la agenda pública y se crean las condiciones políticas para la ejecución de un conjunto de reformas encaminadas a implantar un nuevo orden centrado en el mercado. Aparte del énfasis en reformas económicas tales como la privatización, la liberalización comercial y la apertura externa, se desencadena el proceso de las reformas constitucionales. Se inició una fase de desconstrucción legal e institucional que abriría el camino para la refundación del Estado y de la sociedad, de acuerdo con los nuevos parámetros consagrados internacionalmente. La desregulación, que da paso a una nueva regulación, asumió el primer plano de los debates, adquiriendo condiciones políticas de viabilidad, al mismo tiempo que se fortalecen, con el amplio apoyo de los medios de comunicación, los soportes ideológicos del nuevo modelo. Las metas sociales son progresivamente desplazadas de la agenda. Ésta se vuelve cada vez más restrictiva y adquiere mayor rigidez en torno de las metas de estabilización y ajuste fiscal. De acuerdo con las nuevas directrices, aumentos de gastos en programas sociales y proyectos desarrollistas no sólo serían desaconsejables sino perjudiciales, representando un riesgo de regreso al populismo económico.

Paralelamente, respecto al grado de movilización y de organización de la sociedad civil, grandes contrastes separan la década de los 90 de los años 80, cuya marca fue la efervescencia social y política. Efectivamente, la observación de la sociedad brasileña de la década de los 80 revela un alto grado de fortalecimiento organizacional, así como altos índices de participación e implicación de los diferentes segmentos de la población en la vida política. Los indicadores son múltiples e inequívocos. La movilización de empresarios y trabajadores en defensa de sus respectivas pautas de demandas, el sustancial aumento de los índices de huelgas en todos los sectores de la actividad económica, la explosión de los movimientos sociales en el campo y la ciudad, la inquietud 
de los sectores medios y populares urbanos, son algunos de los aspectos destacados por los estudios sobre el periodo (Santos, 1985; Boschi, 1987). En contraste, bajo el impacto del avance de la globalización y de la revolución tecnológica, asociado a la drástica reducción del ritmo de crecimiento de la economía e incluso del estancamiento y/o recesión económica, los años 90 revelan el retraimiento de la sociedad y el reflujo del movimiento sindical ${ }^{1}$.

La meta de fundar un nuevo orden, simbolizada por la propuesta de desmantelamiento de la era Vargas, se transforma en bandera política de la coalición dominante. La primacía de la orientación neoliberal y la instauración de un modelo económico centrado en el mercado fueron acompañadas de un proyecto ambicioso de inauguración de una nueva institucionalidad, en la cual no tendrían lugar las antiguas formas de articulación Estado-sociedad. Si el modelo varguista consolidó la representación de la estructura corporativa de los intereses económicos en el interior del aparato estatal, la nueva concepción comandará el proceso de cierre de los foros corporativos en la burocracia pública, en consonancia con el predominio del estilo tecnocrático de gestión. El refuerzo del poder despótico del Estado, en el sentido de Michael Mann (Mann, 1986), se tradujo en el ensanchamiento del espectro de acciones que las elites estatales estarían capacitadas para emprender sin la negociación institucionalizada con los grupos de la sociedad civil. Esta situación resultó de la confluencia de algunos procesos simultáneamente desencadenados, tales como la concentración del poder de toma de decisiones en la alta tecnocracia gubernamental en lo tocante a las decisiones de política macroeconómica -área ésta a ser protegida de ingerencia externa- la expansión de las prerrogativas legislativas del Ejecutivo, por medio del uso exacerbado de las medidas provisionales, así como el alto grado de insularidad burocrática, en nombre de la preservación de la racionalidad técnica de las políticas².

Otro tipo de contraste adquiere visibilidad en los años 90. Se trata del descompás entre, por un lado, la lógica concentradora que busca aislar las altas instancias administrativas del gobierno federal de la interferencia de las fuerzas sociales y políticas y, por otro, la apertura del proceso de toma de decisiones en el ámbito municipal, dada la diseminación en esta esfera del poder de las experiencias de gobierno y de ensayos de reforma del Estado más afinados con el ahondamiento de las prácticas democráticas y con un estilo más participativo de gestión. De esta manera, bajo la hegemonía del pensamiento neoliberal, la primacía del paradigma tecnocrático comandó la reestructuración de la burocracia federal. De acuerdo con tales directrices, con independencia del régimen político en vigor, eficiencia gubernamental sería el resultado de un proceso de concentración, centralización y cierre del proceso de toma de decisiones, siendo la eficacia de gestión subordinada a las prácticas de clausura burocrática. En

1. Para un análisis competente del movimiento sindical en los años 90, véase CARDOSO (1999a y 1999b).

2. Me refiero aquí básicamente a las áreas de política monetaria, de cambio, crédito y comercio exterior, así como a la propia política industrial, que también fue mantenida confinada en el interior del aparato burocrático (RUA y AgUiAR, 1995; DinIZ, 1997). 
contraposición, en la esfera local, se abrieron espacios para experimentos alternativos, con la instauración de prácticas basadas en arreglos tripartitos de negociación, implicando la diversificación del abanico de actores admitidos en diversas instancias decisorias y deliberativas, así como la cooperación entre representantes de la sociedad civil y técnicos del gobierno, con objeto de definir las prioridades de la agenda gubernamental y la asignación de los recursos públicos.

Finalmente, las políticas liberales y la ejecución de la agenda de reformas tuvieron consecuencias decisivas en el cambio del perfil económico y social del país. Ineficaces para retomar el desarrollo, con nuevas bases, estas reformas tuvieron, por otro lado, alto grado de eficacia en el desmantelamiento de los cimientos del antiguo orden, volviendo anacrónico cualquier intento de regreso al pasado. En efecto, bajo el impacto de la globalización y de la primacía de las directrices neoliberales, se opera una drástica redefinición de las bases del capitalismo industrial brasileño, observándose una diferencia característica con relación a las fases anteriores del proceso de industrialización. La implementación de las reformas orientadas al mercado, principalmente profundizando en el proceso de privatización y con la apertura externa de la economía, privilegiando la atracción de capitales externos, desencadenó una amplia reestructuración del parque industrial, motivando quiebras, adquisiciones, fusiones y la formación de grandes conglomerados, capitaneados por el capital internacional. La desnacionalización de la economía alcanzó proporciones hasta entonces inéditas. En consecuencia, el espacio de la empresa privada nacional se estrechó cada vez más. En las etapas anteriores, en consonancia con la estrategia de consolidar la industrialización por sustitución de importaciones, se privilegió la meta de crear una burguesía nacional fuerte. Este objetivo, definido en las fases iniciales de la industrialización sustitutiva, tuvo continuidad ya fuera bajo la vigencia del nacional-desarrollismo, entre los años 50 y 60, ya bajo la égida de las directrices consagradas por los gobiernos militares (1964-1985), responsables de la implantación del modelo del trípode, basado en un equilibrio relativo entre empresa estatal, extranjera y nacional, según la fórmula desarrollo-seguridad nacional. Bajo sus diferentes configuraciones, por lo tanto, la coalición desarrollista confirió un peso específico a la empresa nacional, que ocupaba un espacio bien demarcado entre los demás agentes dinámicos de la economía. En otras palabras, esta empresa tenía un significado económico, ocupaba una posición reconocida y cumplía un papel político en cuanto integrante del pacto de sustentación de la estrategia de desarrollo en vigor.

En contraste, en los años 90, en el periodo posterior a las reformas, el empresariado nacional se agota como protagonista del nuevo orden económico y como categoría política, privado de la alianza que le había sido concedida y del papel que le fue conferido por las estrategias desarrollistas del pasado. Al abrigo de las nuevas directrices pro-mercado, es la lógica concentradora de las grandes corporaciones transnacionales que comanda el nuevo orden económico, cuya prioridad es la inserción-integración de las economías nacionales en una estructura de poder de escopo transnacional. Sólo una fracción muy restringida del empresariado local, en general asociada a los grandes conglomerados, tiene condiciones para participar en esta estructura. Los demás segmentos operan bajo condiciones altamente desfavorables, en el límite de la supervivencia. 
Gran parte pereció. Los que garantizaron su supervivencia por medio de la fusión o asociación con empresas líderes internacionales tienen su suerte encadenada al éxito de la estrategia dominante. De este modo, además de la progresiva concentración industrial típica de la globalización, se verificó un proceso de desnacionalización de las elites empresariales, dada la intensificación de la internacionalización de las empresas líderes del nuevo orden económico, configurando un corte no sólo económico, sino también político en relación con el antiguo modelo.

En contrapartida, al final de la década se amplió el descontento con el actual modelo, intensificándose la búsqueda de alternativas y reactivándose la discusión en torno a nuevas estrategias de desarrollo. Tal tendencia se acentuaría con el agravamiento de las restricciones externas asociadas a los desdoblamientos del proceso de globalización y a las sucesivas crisis que sacudieron el mercado internacional entre 1997 y 1999. Otro punto que alimentó el debate fue la identificación de las dificultades para encontrar formas de integración en el sistema internacional compatibles con mayores grados de autonomía decisoria nacional. La ruptura del consenso alrededor de la agenda neoliberal se alimentó de la protesta de sectores del empresariado, aunque los contornos de una estrategia alternativa no estuvieran claramente definidos, ni se vislumbrase la posibilidad de un amplio apoyo a una nueva coalición política.

\section{EL CORPORATIVISMO Y LAS RELACIONES PÚBLICO-PRIVADO EN UNA PERSPECTIVA HISTÓRICA: 1930-1985}

La observación de la trayectoria del capitalismo industrial brasileño por la vía de la industrialización por sustitución de importaciones, entre las décadas de los 30 y los 70, revela un alto grado de continuidad institucional, a pesar de los cambios de régimen político, con la alternancia entre democracia y autoritarismo, expresión de la inestabilidad política del país en aquel periodo. Esta continuidad está representada por la tradición centralista-intervencionista del Estado, por las formas dominantes de articulación Estado-sociedad, por el patrón de incorporación de actores estratégicos al sistema político, mediante la instauración del corporativismo-estatal y, finalmente, por el modelo de presidencialismo que se implantó, fuertemente concentrador de prerrogativas en el Ejecutivo, dando origen al que fue llamado en la literatura modelo estadocéntrico.

En lo que respecta al sistema de representación de intereses del empresariado industrial, desde los inicios de la industrialización en los años 30 hasta el presente momento, prevaleció la estructura dual integrada por las organizaciones corporativas oficiales y las asociaciones paralelas o extra-corporativas, que mantenían, a lo largo del tiempo, funciones complementarias, alternando relaciones cooperativas o conflictivas, conforme a las diferentes coyunturas políticas (Diniz y Boschi, 1979; Diniz y Boschi, 1991; Costa, 1999; Leopoldi, 1984). La estructura corporativa creada por el presidente Getúlio Vargas en los años 30 estaba formada por los sindicatos, organizados por ramos de actividad y de base local, por las federaciones representando a las industrias de cada estado y por una confederación, órgano de cúpula, que representaba al conjunto de la 
industria nacional. Integrada en la CLT (Consolidación de las Leyes del Trabajo), esta estructura quedó subordinada a una legislación específica, pautando su funcionamiento por la garantía del monopolio de la representación de los intereses de cada categoría funcional, por el principio de la unicidad sindical y por la obligatoriedad de la contribución financiera, independiente de la filiación. Por otro lado, la estructura extra-corporativa estaba constituida por las asociaciones civiles voluntarias, sectoriales y de ámbito nacional, funcionando de manera autónoma respecto a la legislación sindical. Aunque implantadas desde el inicio del proceso de industrialización, estas asociaciones se expandieron de forma particularmente intensa durante los dos principales impulsos desarrollistas, en los años 50 y en el periodo correspondiente al llamado Milagro Económico de los gobiernos militares, entre la mitad de los años 60 y $70^{3}$.

Durante este último periodo, la sociedad brasileña alcanzó los más altos índices de crecimiento económico e industrial de su historia, lo que se tradujo en una organización social cada vez más compleja y diferenciada. Estas tendencias fueron estimuladas además por las transformaciones políticas originadas por la gradual apertura del régimen y el patrón de transición negociada que condujo a la instauración de la democracia, entre 1975-1985. La fuerza y autonomía crecientes de la sociedad civil, la proliferación de nuevas formas de organización y de participación política sacudieron las antiguas formas de control estatal. A partir de entonces, la persistencia de la estructura dual antes descrita se acompaña de cambios en el sentido de una mayor flexibilidad, configurándose una red de intereses extremamente compleja y diversificada. Incorporando a la mayor parte de los sectores industriales del país y, en algunos casos, cadenas productivas de gran peso económico, las asociaciones paralelas, a partir de mediados de los años 70, adquirieron mayor dinamismo y capacidad de representación frente a las organizaciones corporativas que, por el contrario, experimentaron un gradual vaciado y pérdida de prestigio.

La evolución continuó durante las varias décadas de desarrollo de la ISI y, ya a finales de los años 80, el sistema de representación empresarial se volvió aún más complejo con la creación de las denominadas nuevas organizaciones empresariales, como el IEDI (Instituto de Estudios para el Desarrollo Industrial), el PNBE (Pensamiento Nacional de las Bases Empresariales) y los varios Institutos Liberales, localizados en los principales centros industriales del país. Estas organizaciones surgieron para llenar lo que los empresarios consideraban una laguna en el campo de la producción de ideas y de la difusión de principios ideológicos relacionados con el desarrollo del capitalismo brasileño. El IEDI, por ejemplo, que tuvo su auge entre los años 1989 y 1993, se destacó en la producción de estudios y propuestas dirigidos a la formulación de una

3. Entre las principales asociaciones de este tipo, podemos citar la ABDIB (Asociación Brasileña de las Industrias de Base), la ANFAVEA (Asociación Nacional de Fabricantes de Vehículos Automotores), la ABINEE (Asociación Brasileña de la Industria de Electrodomésticos), la ABIMAQ (Asociación Brasileña de la Industria de Máquinas y Equipamientos), la ANFPC (Asociación Nacional de los Fabricantes de Papel y Celulosa), la ABIA (Asociación Brasileña de la Industria de Alimentos), la ABIFARMA (Asociación Brasileña de la Industria Farmacéutica), la ABIQUim (Asociación Brasileña de la Industria Química) y la APEOP (Asociación de los Contratistas de Obras Públicas). 
política industrial capaz de orientar el proceso de inserción del país en el mercado global, preservando de forma simultánea el espacio de la producción interna. En el periodo siguiente, entre 1994 y 1998, estas organizaciones experimentaron un cierto vaciado, especialmente el IEDI, lo que podría estar relacionado con el éxito de las prioridades de la nueva agenda pública y con la implementación de las reformas orientadas al mercado, que implicaron la desaparición de la política industrial como objetivo legítimo de la acción gubernamental.

De esta forma, el fortalecimiento de la industrialización se acompañó de la expansión y diversificación de las organizaciones empresariales. Los años 80 determinaron una reestructuración del sistema en su conjunto, con cambios de peso e importancia relativos de algunos sectores, reforzándose la tendencia general a la especialización y multiplicidad de los canales a disposición de los diferentes segmentos empresariales. Se evolucionó hacia la configuración de un sistema híbrido y multipolar (Diniz y Boschi, 1991), acarreando la quiebra del monopolio de la representación vía estructura corporativa. Ésta, aunque no haya sido eliminada, sufrió un proceso de debilitamiento y pasó a jugar un papel complementario, perdiendo la centralidad que le fuera atribuida por el modelo varguista.

A pesar, sin embargo, de la modernización y profesionalización que tuvieron lugar a partir de la década de los 70 y que se intensificaron en los años 90, un punto de marcada continuidad sería la ausencia de una instancia superior dotada de una elevada capacidad de aglutinación, capaz de articular intereses transponiendo las divisiones sectoriales. La falta de una entidad de cúpula de alto grado de alcance y poder de agregación persistiría como un factor de bloqueo de las prácticas de pactos y alianzas supra-sectoriales, haciendo inviable todavía el surgimiento de una instancia capaz de funcionar como portavoz de la clase empresarial entendida como un todo. Acciones conjuntas y estratégicas de concertación, típicas del neocorporativismo europeo, fueron siempre extrañas al modelo aquí implantado. En este aspecto se perpetuó un rasgo históricamente arraigado, marcado por la segmentación y diversidad de los intereses, aspecto en gran parte responsable de la fragilidad del empresariado brasileño como actor colectivo y de las dificultades del sector en la articulación de plataformas de mayor amplitud y ámbito. Esfuerzos en el sentido de la creación de entidades de cúpula de carácter integrador fueron dispersos y tuvieron una vigencia circunstancial. La UBE (Unión Brasileña de Empresarios), que nació con el objetivo de representar los intereses del conjunto del empresariado en la Constituyente, fue desactivada después del cierre de los trabajos de promulgación de la nueva Constitución, y no hubo otro intento de crear una organización semejante en el transcurso de los años 90 (Diniz y Boschi, 1989).

La tradición corporativa en Brasil consagró la representación de intereses en el interior del aparato del Estado, limitando sin embargo esta representación a áreas específicas de la política económica -como la definición de medidas proteccionistas, la concesión de incentivos y subsidios- así como a ciertos estados del proceso de toma de decisiones, principalmente la consulta y la implementación. Se institucionalizó la práctica de la negociación compartimentada entre los grupos económicos y el Estado, transformándose el Ejecutivo en foro privilegiado para encaminar las demandas empresariales. 
En esta instancia, las negociaciones entre los sectores público y privado serían procesadas sin la interferencia de fuerzas externas, protegidas del juego político y distantes de los mecanismos de control público.

Es necesario aún resaltar que el corporativismo estatal hizo viable la participación de las elites industriales en las estructuras de toma de decisiones, pero excluyó a los trabajadores como socios de los acuerdos corporativos en torno a las políticas económicas de mayor relieve. La participación de los trabajadores sometida al control del Ministerio del Trabajo, quedó circunscrita a las políticas laboral y de seguridad social. Prevaleció un estilo de negociación bipartito, incluyendo representantes empresariales y funcionarios gubernamentales alrededor de políticas sectoriales. A lo largo de las varias fases de la industrialización sustitutiva de importaciones, se expandieron los foros de negociación entre los sectores público y privado, con el fortalecimiento de los consejos técnicos dotados de representación empresarial. Órganos como el CDI (Consejo de Desarrollo Industrial), el CPA (Consejo de Política Aduanera), la CACEX (Cartera de Comercio Exterior del Bando de Brasil), los Grupos Ejecutivos del Gobierno Kubitschek, el CMN (Consejo Monetario Nacional), el CDE (Consejo de Desarrollo Económico) y el CIP (Consejo Interministerial de Precios), por citar tan sólo a los más conocidos, representaron importantes espacios de participación de las elites empresariales en el proceso de toma de decisiones gubernamental ${ }^{4}$. Este rasgo, exacerbado por la larga duración de los regímenes autoritarios, llevó al estrechamiento del intercambio y de los vínculos entre los intereses públicos y privados, originando la privatización del Estado, y ampliando las oportunidades de desperdicios y distorsiones graves en la asignación de recursos.

Finalmente, cabe resaltar un último punto. En el contexto del corporativismo implantado en Brasil, el empresariado desarrolló un estilo de actuación tópico y un patrón fragmentado de demandas, experimentando una gran dificultad para trascender la óptica de sus intereses más específicos. Se configuró como un actor político desprovisto de una percepción a largo plazo y de visión de conjunto, lo que ciertamente tuvo alguna relación con el hecho de haber surgido y madurado bajo regímenes autoritarios. Los parámetros de convivencia y los marcos institucionales responsables de la reglamentación de las relaciones capital-trabajo no estimularon acuerdos inter-clase o pactos tripartitos.

Atrapados en una visión restringida y particularista, y una práctica de maximización de los beneficios inmediatos, los empresarios revelaron una débil disponibilidad y una reducida apertura para enfrentar las cuestiones sociales, ligadas a la reducción de la desigualdad en la distribución de la riqueza y en el acceso a los beneficios generados por el desarrollo económico. Siempre que salieron a la superficie, bajo el impacto de movimientos de base popular, las reformas sociales fueron percibidas principalmente bajo la óptica del aumento de los costos de las actividades empresariales y, por tanto,

4. Innumerables trabajos estudiaron este formato de articulación entre los sectores público y privado en la producción de políticas públicas entre los años 30 y 80. Véase, por ejemplo, DiNIZ (1978), BosCHi (1979), Lima Jr. y ABRANCHES (orgs.) (1987), CASTRO SANTOS (1993), TÁPIA (1995) y LEOPOLDI (1992). 
como un mal a ser evitado o una amenaza a ser vencida. Durante los años 80 , el avance del proceso de globalización y el predominio de las directrices neoliberales, no produjeron la reversión de tales tendencias. Estudios realizados en 1991 y 1993 no mostraron el declive de la distancia ideológica, sino su fortalecimiento, traducido en el contraste entre una subcultura sindical con fuerte énfasis en la dimensión social de la democracia y una visión empresarial unilateralmente identificada con los valores ligados al aumento de la eficiencia y lucro de las actividades empresariales en el proceso de reestructuración productiva en curso (Diniz y Boschi, 1993 a y b; Lima y Cheibub, 1994; Diniz y Boschi, 1997). Posteriormente, Ignácio Delgado (2001) muestra, basándose en amplia documentación, cómo en los años 90, bajo el impacto de la globalización y de la apertura externa de la economía brasileña, los empresarios reforzaron la tendencia histórica de evaluar los derechos sociales bajo el prisma del aumento del llamado costo Brasil (Delgado, 1999, especialmente cap. 4). Junto a la unicidad sindical y la contribución compulsoria, éste fue uno de los aspectos del legado del antiguo orden con un más alto grado de persistencia a lo largo del tiempo.

\section{LA INNOVACIÓN INSTITUCIONAL REPRESENTADA POR LAS CÁMARAS SECTORIALES: ACUERDO TRIPARTITO Y GOBERNANZA ECONÓMICA}

Esta larga línea de continuidad en lo referido a los mecanismos institucionales de articulación Estado-sociedad sufriría cambios significativos en el transcurso de la década de los 90. Bajo el impacto de la crisis a escala mundial de los años 80 y de la configuración de un nuevo orden internacional, se observó, como hemos visto, una fuerte presión externa en el sentido de redefinir la agenda pública. Temas como el retroceso del Estado, la privatización, la apertura externa de la economía, la desregulación, la integración en el orden mundial globalizado se volvieron preponderantes. Al lado de los programas de estabilización económica, las reformas orientadas al mercado pasaron a dominar la agenda pública en los diferentes países latinoamericanos, aunque el orden de prioridades y el ritmo de ejecución varíen en cada caso.

Como ya fue destacado, en Brasil el marco de este proceso fue el gobierno del presidente Fernando Collor de Mello, cuya elección se vio favorecida por los efectos de la crisis de gobernabilidad experimentada por el país a partir de los últimos años del gobierno Sarney. Se creó un clima de descrédito generalizado en las instituciones y en los gobernantes, así como un fuerte sentimiento de rechazo al status quo. Es en este contexto que se observan las condiciones propicias para el éxito de un candidato antiestablishment, que pasa a priorizar las directrices identificadas en el llamado «Consenso de Washington». En este momento, se verifica una drástica redefinición de rumbos, determinando el estrechamiento y la rigidez de la agenda pública, con la centralidad atribuida a los programas de estabilización y al denominado ajuste estructural. Como derivación de la nueva postura oficial, las reformas sociales pierden prioridad, siendo de hecho descartadas de la agenda. Por otro lado, la reforma del Estado se destaca, incorporándose al programa del gobierno tras la investidura del presidente. 
Bajo la égida de las directrices neoliberales, lo que prevaleció durante el gobierno Collor fue una concepción minimalista de reforma del Estado. A la luz del enfoque reduccionista dominante, los reformadores privilegian las metas de recorte de gastos y reducción del déficit público, lo que se tradujo en un esfuerzo para enjugar la máquina estatal. Recortes de personal y extinción de órganos sin criterios claros implicaron de hecho la mutilación del aparato burocrático, agravando los problemas de irracionalidad e ineficacia heredados del antiguo orden. Se observó el predominio de una agenda negativa de desmantelamiento del legado del pasado, en franco descompás en relación con la complejidad de las tareas a ser desempeñadas por el Estado en un mundo globalizado, en que competitividad y capacidad de inserción estratégica se vuelven claves para el éxito. Una visión más pertinente implicaría trasladar el énfasis a la redefinición del papel y a la reestructuración del aparato estatal, restringiendo en algunos sectores y ampliando en otros la participación del Estado, teniendo en cuenta sobre todo la mejoría de la calidad de la Administración pública.

Un segundo aspecto de la reforma emprendida en este periodo fue la radicalización de la centralización del poder en la cúpula tecnocrática, con la creación del Ministerio de la Economía, un superministerio que englobó tres antiguos ministerios más algunas secretarias de la Administración anterior. En la estela de este proceso se verificó el cierre de gran parte de los foros corporativos, que hasta el gobierno anterior todavía habían funcionado en el interior de la burocracia gubernamental. En el ámbito de la política industrial, por ejemplo, se extinguieron el CDI, la CPA, el CIP y otros diversos consejos y comisiones anteriormente encargados de la formulación e implementación de políticas sectoriales y de decisiones en el área del fomento de la producción industrial (Diniz, 1997: 146). De acuerdo con la primacía atribuida a las metas de estabilización y ajuste, para muchos de los nuevos integrantes del equipo económico la política industrial sería, por lo demás, irrelevante.

Fue dentro de este contexto de aislamiento burocrático y de predominio del estilo tecnocrático de gestión, que se crearon, a inicios de los años 90, las Cámaras Sectoriales, concebidas como foros de negociación para la articulación de acuerdos en torno de políticas sectoriales. Reuniendo representantes empresariales y líderes sindicales, junto a técnicos y decisores gubernamentales, las Cámaras Sectoriales inauguran un patrón tripartito de negociación, consagrado internacionalmente por el corporativismo europeo. Esta característica llevó a autores que se dedicaron al estudio de la más significativa de estas cámaras, la de la industria de automoción, a afirmar que se trataba de la introducción del neocorporativismo en Brasil. En otros trabajos ${ }^{5}$, tuve la oportunidad de refutar ampliamente este tipo de interpretación, razón por la cual apenas haré una breve alusión al tema, abordando algunos puntos que me parecen esenciales.

Como ya fue destacado, la construcción del capitalismo industrial en el país tuvo como telón de fondo una ingeniería político-institucional que agregaría los intereses en categorías jerarquizadas y no competitivas, observándose la articulación directa entre los sectores público y privado por la vía del corporativismo sin la mediación partidaria.

5. Véase principalmente DiNIZ (1994b: 296-303) y DiNIZ (1997: 160-187). 
Se institucionalizó una sistemática de negociación de carácter sectorial y bipartita entre representantes del empresariado e integrantes de los altos escalones burocráticos. De esta sociedad, quedarían excluidos los trabajadores sindicalizados, cuya participación sería admitida para áreas más específicas, como la política laboral.

Es en este sentido que se puede apuntar el impacto innovador de las prácticas inauguradas por las Cámaras Sectoriales, ya que consagraron una sistemática de negociación tripartita en que los trabajadores aparecen como interlocutores legítimos, determinando, por tanto, la ruptura de la relación diádica y excluyente de la tradición corporativa en Brasil. Se trata en realidad del pleno aprovechamiento de las virtualidades del modelo corporativo que, en la variante que predominó entre las décadas de los 30 y 70, estuvieron infrautilizadas. En primer lugar, el patrón de tutela y de ingerencia del Estado históricamente consolidado hizo inviable la resolución del conflicto distributivo por la negociación autónoma entre las partes interesadas. En segundo lugar, la marginalización de la representación de los trabajadores contuvo la negociación típica de este sistema dentro de parámetros demasiado restringidos. Finalmente, el carácter tópico y localizado de los acuerdos obstaculizó la evolución en la dirección de una amplia asociación con el Estado, en virtud de la reducida representatividad de los intereses en juego, del peso de los nexos clientelistas y del alcance limitado de las cuestiones negociadas.

Al legitimar al trabajador sindicado como interlocutor, el mecanismo en que se basó el funcionamiento de las Cámaras Sectoriales permitió ensanchar el ámbito de las negociaciones entre los actores básicos del orden industrial, eliminando la práctica tradicional de los arreglos directos entre grandes empresarios y gobierno, sacudiendo la dinámica del Estado preso de los intereses de clientelas privadas. Por otro lado, esta sistemática no garantiza por sí misma la ruptura con la sectorización de los intereses, inducida por la configuración monopolista del mercado, típica del sistema corporativo brasileño. De forma similar, tal mecanismo no significa automáticamente la garantía de que prevalezca la óptica del interés público y la subordinación de las negociaciones entre las partes interesadas a criterios de carácter incluyente y alcance general. Este tipo de cambio exigiría una serie de condiciones adicionales, tales como, por parte de las entidades de clase, la presencia de organizaciones incluyentes de alto poder de agregación y, del lado de las agencias gubernamentales, una fuerte capacidad de coordinación.

Entre tanto, la estrategia empresarial de enfrentamiento de la crisis, que se abatió sobre la economía brasileña durante los dos primeros gobiernos de la Nueva República aumentando la deuda externa y la aceleración del proceso inflacionario, no se orientó hacia revertir la fragmentación a favor de formas más unitarias de actuación. Al contrario, la reacción a las políticas gubernamentales de los años 80 llevó al ahondamiento de la diferenciación y de la dispersión. Junto a los sindicatos integrantes de la estructura corporativa y de las asociaciones paralelas, se crearon nuevas organizaciones, yuxtapuestas a las antiguas, que representaban canales adicionales de participación, volviendo todavía más compleja la estructura dual de representación históricamente consolidada. Además, a partir de la instauración de la Nueva República, se generalizó la práctica del lobby empresarial, que se consagró como una modalidad rutinaria de 
presión sobre los poderes públicos. Desde los trabajos del Congreso Constituyente, este estilo de actuación por la vía del lobby pasó a ocupar un espacio cada vez mayor, no sólo en función de la importancia asumida por la actividad parlamentaria, sino también en consecuencia del ya aludido cierre de los antiguos foros de representación corporativa en el interior de la burocracia gubernamental.

El mayor pluralismo de los órganos de representación empresarial tuvo como resultado un aumento de la diversidad y del conflicto, tendencia que se agravó por la inexistencia de una entidad de cúpula de carácter amplio y supra-sectorial, capaz de atenuar los efectos combinados de las divisiones sectoriales, regionales o relativas al porte de las empresas. Éste fue, además, uno de los factores responsables de la inviabilidad de los pactos en torno a los programas de estabilización económica, ensayados por los dos primeros gobiernos de la Nueva República (Diniz, 1997: 94-104). La ausencia de interlocutores reconocidos por el conjunto de las clases empresariales y trabajadoras como sus portavoces legítimos crearía expectativas negativas respecto a la posibilidad de que los pactos eventualmente articulados por los liderazgos fueran acatados.

Por otro lado, aunque no hayan alterado radicalmente el alcance del corporativismo brasileño, las Cámaras Sectoriales constituyeron un importante instrumento de política industrial. Como destaqué en otros trabajos, representaron, de hecho, una experiencia de economic governance, en el interior de una burocracia cada vez más afecta al estilo aislado y tecnocrático de gestión. El concepto, introducido recientemente por la literatura internacional, se refiere a una nueva forma de abordar la cuestión de la eficacia de la acción estatal, con énfasis en el sostenimiento político de las decisiones. En este sentido, gobernanza significa la capacidad del gobierno para resolver aspectos de la pauta de problemas del país a través de la formulación y de la implementación de las políticas pertinentes, o sea, tomar y ejecutar decisiones, garantizando su continuidad en el tiempo y su efectivo acatamiento por parte de los segmentos afectados. En otras palabras, la noción de gobernanza económica incluye no sólo la capacidad del gobierno para tomar decisiones con presteza, sino también y sobre todo, su habilidad para crear coaliciones de apoyo a sus políticas, generando adhesiones y condiciones para prácticas cooperativas, aumentando sustancialmente la eficacia del proceso de implementación ${ }^{6}$.

Esta experiencia de creación de un espacio institucional destinado a integrar procesos de formulación de políticas y de articulación de intereses se mostró relativamente eficaz en el caso de los acuerdos de la industria de automoción (marzo de 1992, febrero de 1993 y febrero de 1995) haciendo viable un ajuste creativo frente a la crisis estimulada por la apertura comercial (Diniz, 1997: 169-170). De este modo se diversificaron las metas iniciales, pasando a incluir la apertura del mercado paralelamente al mantenimiento de un saldo positivo en la balanza comercial del sector, la renovación tecnológica de la base productiva, un nuevo mix de producción, con énfasis en los modelos

6. Es grande el número de autores que tratan esta cuestión, entre los cuales me gustaría destacar a COHEN y Rogers, 1995; COHEN, 1998; Hollingsworth, SCHMitTER y StreECK, 1994; ConAgHAN y MALloy, 1994; LOCKE, 1995. Para una reseña de esta literatura, véase DinIZ, 1998. 
populares de automóviles, el aumento del empleo y de los salarios y una nueva estructura tributaria sectorial. Los acuerdos firmados en 1992 y 1993 alcanzaron los objetivos estipulados, repercutiendo en el conjunto de la cadena productiva. Conjugando la reducción de los precios y de la carga fiscal sobre los automóviles con la consecución de ciertas metas básicas, como retomar las inversiones, el mantenimiento del nivel del empleo y la reestructuración productiva del sector, las negociaciones posibilitaron el fortalecimiento y la mejoría del desempeño del complejo de la automoción como un todo. Se obtuvo la recuperación de los niveles de producción con la preservación de los niveles de empleo entre 1992 y 1995, deteniendo la caída abrupta verificada entre 1990 y 1992. Lejos de experimentar una fuerte reducción, como preveían sus críticos, los acuerdos de la industria de la automoción propiciaron un significativo aumento de la recaudación. Además, las cámaras constituyeron un importante espacio para el desencadenamiento de una discusión sobre formas de colaboración entre capital, trabajo y gobierno, considerando la implementación de políticas sectoriales concertadas, rompiendo con las prácticas históricamente arraigadas de negociaciones bipartitas.

Sometidas a una sistemática de funcionamiento intermitente y transitorio, entre 1991 y 1995, las cámaras tuvieron, sin embargo, efectos limitados. Las condiciones institucionales y políticas de aquella coyuntura no fueron favorables a este tipo de experimento, que acabó por configurarse como un esfuerzo localizado, con débil poder de reproducción, despertando fuertes resistencias en el interior del propio equipo económico del gobierno, bastante identificado con un estilo centralizado de gestión económica. Esta postura fue la responsable de la condenación de las Cámaras Sectoriales bajo el argumento de que se trataba de un contubernio entre intereses corporativos y elites gubernamentales para la defensa de privilegios de un grupo restringido, en detrimento del conjunto de la sociedad (Franco, 1993 a y b). La visión de las elites tecnocráticas, francamente contraria a la apertura de espacios de negociación en el interior del aparato estatal para la discusión de la política económica en general y, particularmente, para la formulación de política industrial, fue uno de los factores responsables del vaciado de las Cámaras Sectoriales a partir de 1995 (Arbix, 1997, 2000). El fin de la experiencia no fue fruto de su agotamiento, sino de una acción deliberada del gobierno con el objetivo de desmontar los foros corporativos de negociación en favor del libre mercado.

La ruptura tuvo lugar con el advenimiento del gobierno de Fernando Henrique Cardoso, cuando la coalición nacional-desarrollista se disgrega, bajo la hegemonía de las directrices neoliberales. Bajo la orientación del nuevo presidente, las elites estatales adoptan un estilo centralizador de gestión, optando por ahondar en la práctica del aislamiento burocrático de las decisiones, sistema bajo el que fueron elaboradas las reglas del régimen de la automoción a partir de 1995. Mediante un complejo legal, constituido por la edición de Medidas Provisionales ${ }^{7}$, el gobierno estableció las bases del régimen de

7. Véase la lista de MPs de 1995-1996 (MP 1.024, de 13/06/95, MP 1.235, de 14/12/95 y MP 1.483, de 05/02/96) y de varios Decretos (Decr. 1.761, de 26/12/95, Decr. 1.863, de 16/04/96, Decr. 1.987, de 20/08/96), responsables de la definición del nuevo régimen del sector de la automoción. 
automoción posteriormente regulado a través de la Ley 9.449 y del Decreto 2.072 de noviembre de 1996 (De Negri, 1998: 3).

En contraste con las expectativas de los críticos de las Cámaras Sectoriales, éstas fueron eliminadas pero las decisiones relativas al sector no se volvieron por ello más racionales, más eficaces o más afinadas con el interés público. En un estudio de 1998, João Alberto de Negri, investigador del IPEA, llamó la atención sobre los efectos contradictorios del régimen instaurado en 1996 en la automoción para atraer inversiones de los fabricantes de vehículos en Brasil y aumentar las exportaciones. Las políticas puestas en práctica determinaron un aumento sustancial de los lucros de las montadoras, paralelamente al estrangulamiento de las empresas de autopiezas y el incremento de los costes para el consumidor debido al aumento de los precios reales medios de los vehículos (De Negri, 1998). Las consecuencias negativas de esta política saldrían también a la superficie a través del amplio debate que se trabó en la prensa en torno a las decisiones altamente polémicas de finales de los años 90, implicando a los gobiernos de Rio Grande do Sul y Bahia por atraer inversiones de grandes montadoras (Carta Capital, 21 de julio de 1999). Cuestiones complejas, como el instigamiento de la llamada guerra fiscal entre estados y municipios del país, la desnacionalización del sector de autopiezas y los altos índices de renuncia fiscal, principalmente a través de la exención de impuestos municipales, como el IPTU (Impuesto Inmobiliario y Territorial Urbano) y el ISS (Impuesto sobre Servicios) revelan un balance claramente favorable a la apropiación de las ganancias por parte de las montadoras, en detrimento de los demás sectores. Como resalta Arbix:

Más allá de las fricciones políticas y económicas entre los estados, otra resultante de este proceso apunta a la pérdida de la capacidad de planeamiento y de control efectivo de los poderes públicos sobre las estrategias de desarrollo. En lugar del Estado central, que invertía y producía directamente por intermedio de sus empresas y autarquías -lo que realzaba el papel de los staffs públicos de elaboración e implementación de políticas- surgen ahora gobiernos estatales y municipales que, orientados por esta disputa, acaban por subordinar sus políticas de desarrollo a las estrategias privadas, comportándose muchas veces como avalistas y portavoces de estos intereses a priori identificados con el interés público. Como corolario, en los gobiernos subnacionales que más se comprometieron con esta guerra, las negociaciones entre el sector público y los grupos privados se realizan a puerta cerrada y anunciadas -cuando lo son- sólo cuando los acuerdos ya han sido de hecho celebrados (Arbix, 2000: 30).

\section{LA DÉCADA DE LOS 90: PATRÓN DE ACCIÓN ESTATAL Y FORMAS DE ARTICULACIÓN PÚBLICO-PRIVADO}

Como fue resaltado anteriormente, lejos de reflejar apenas la acción de procesos histórico-estructurales, los cambios institucionales de los años 90 fueron el resultado en gran parte de una acción deliberada del Estado, objetivando el llamado desmantelamiento de la era Vargas. La ejecución de las reformas constitucionales por la vía del Congreso 
y el patrón de implementación de las reformas orientadas al mercado, ambos prioridades de la agenda del presidente Fernando Henrique Cardoso, harían posible la consecución de tales metas. A partir de la segunda mitad de los años 90, la ejecución de esta agenda marcó el fortalecimiento de la ruptura con el antiguo orden y lanzó las bases de un nuevo régimen de incentivos y regulaciones. Progresivamente, el Estado aumenta su autonomía en relación con la sociedad y con el sistema representativo, al mismo tiempo que se observa el estrechamiento de vínculos con el nuevo orden internacional. Además de los factores exógenos, es preciso, por tanto, considerar las características cambiantes de las relaciones entre los sectores público y privado como resultado de las elecciones y acciones de las elites estatales. En consonancia con las prioridades de la agenda, la preocupación por la atracción de capitales e inversiones externos se vuelve preponderante, superponiéndose a los intereses de los grupos empresariales domésticos.

En esta línea de consideraciones, cabe resaltar la relación entre la forma de implementación de estas reformas y la consolidación de la democracia. No basta con considerar las prioridades de la agenda, es necesario tener en cuenta la dimensión políticoinstitucional del proceso de formulación e implementación de políticas, que se traduce en un determinado estilo de gestión pública. Entre los aspectos más relevantes del patrón de acción estatal, se debe mencionar la naturaleza del proceso de toma de decisiones, el grado en que este poder está concentrado en el Ejecutivo, el mayor o menor grado de discrecionalidad de la alta burocracia gubernamental, el patrón de relaciones entre los poderes, particularmente la naturaleza de las relaciones entre el Ejecutivo y el Legislativo, las características de la coalición que sustenta al gobierno, el grado de independencia o de subordinación del Legislativo (por ejemplo, su baja capacidad deliberativa no sólo en lo referido a la política macroeconómica, sino también a ciertas áreas de política, como el comercio exterior y la política industrial) y, finalmente, las formas de articulación entre los sectores público y privado. Así, cabe investigar hasta qué punto el éxito de las reformas orientadas al mercado se obtuvo en un contexto de estímulo de las tensiones entre la modalidad de la implementación y los imperativos del perfeccionamiento democrático, sobre todo en lo referido al ensanchamiento de la participación, a la difusión de los espacios de concertación y a la eficacia de los mecanismos de control externo. Este último aspecto se convierte en particularmente relevante si consideramos que el déficit institucional en cuanto a la efectividad de los instrumentos de accountability constituye una de las principales lagunas del legado del antiguo orden ${ }^{\text {. }}$ Estas son algunas de las principales indagaciones que salen a la superficie cuando se evalúan las transformaciones de la última década.

Un primer aspecto a ser destacado se refiere a la institucionalización del estilo tecnocrático de gestión paralelamente al desmantelamiento de los foros corporativos en el seno del aparato estatal, que convergen en la producción de incentivos para que prevalezcan formas no institucionales de acceso a los núcleos decisorios centrales. En este sentido, el ya referido aumento del poder despótico del Estado se reveló fundamental.

8. En varios trabajos anteriores, llamo la atención sobre el déficit de accountability, característico del proceso de formación del Estado brasileño. Véase DinIZ (1997, 1998 y 2000). 
En este contexto, el uso exacerbado de las Medidas Provisionales representó el refuerzo de una tendencia de larga tradición en el país, la de dotar al Ejecutivo de amplio margen de autonomía, garantizándole primacía en la conducción de la política nacional. Creadas por la Constitución de 1988, a través de su artículo 62, para dar al Ejecutivo los medios para una acción rápida, en casos de relevancia y urgencia, muy pronto las MPs pasaron a ser utilizadas como medio rutinario de gobierno (Diniz, 1997). Aplicadas de modo indiscriminado para hacer viables políticas de emergencia o no, prioritarias o no, las MPs tuvieron su uso banalizado con el paso del tiempo. En este aspecto, destaca de forma eminente el presidente Fernando Henrique Cardoso en sus dos mandatos, durante los cuales el total de estas medidas ultrapasó la marca de 5.000, entre ediciones y reediciones. Aparte del impacto sobre las relaciones Ejecutivo-Legislativo, el uso amplio y sin restricciones de las MPs afectó al ordenamiento jurídico del país, imprimiéndole un alto grado de inestabilidad. La utilización intensa de los poderes legislativos por parte de la Presidencia mediante la sistemática de ediciones y reediciones de las Medidas Provisionales, vulnerando el principio constitucional que restringía su uso a los casos de relevancia y urgencia, unido a los procedimientos referidos, caracterizó el estilo de gestión política que hizo posible la implementación de la agenda de reformas.

Como destaqué en otro trabajo (Diniz, 2000), el modelo aislado de gestión, dominante durante el gobierno Collor, persistió bajo la Presidencia de Fernando Henrique Cardoso, que reforzó la primacía burocrática, atribuyendo papel central al Ministerio de Hacienda, al Banco Central y al Tesoro Nacional, que formarían, junto con el BNDES, el núcleo duro del Estado, responsable de las decisiones estratégicas, sobre todo en lo referido a la política económico-financiera, controlando las informaciones más relevantes, principalmente aquellas que circulan en las instancias internacionales y disponiendo de acceso privilegiado a las decisiones externas. Paralelamente, el patrón de reclutamiento para los altos cargos de este círculo se transforma y pasa a privilegiar las elites estratégicamente introducidas en las redes transnacionales de conexiones.

Las negociaciones llevadas a cabo en el Congreso se desdoblarán dentro de límites definidos previamente por el Ejecutivo. Dentro de esta lógica, lo esencial del proyecto gubernamental -representado por el plano de estabilización económica, por el ajuste fiscal y por las medidas comprometidas con la nueva forma de inserción en la economía internacional- sería innegociable, cabiendo al núcleo tecnocrático, o sea, el equipo económico enclaustrado en el Ministerio de Hacienda y el Banco Central, administrarlo de forma autónoma frente a las fuerzas internas, a través del manejo de los instrumentos mencionados, destacando el amplio uso de las MPs. En este frente, habría una forma radical de actuación marcada por la rigidez e inflexibilidad en la consecución de las metas estipuladas. Por otro lado, en lo que concierne a las reformas y leyes ordinarias, el Congreso se destacaría como el locus de la negociación, resultando algún tipo de conciliación, variando los grados de flexibilidad en función de la fuerza del banco opositor y, ante todo, de las disidencias entre los propios aliados del gobierno.

A la mayor discrecionalidad de la burocracia estatal le correspondería el refuerzo de la tendencia históricamente consolidada de la utilización de vínculos informales y del contacto personal como forma de acceso a las instancias gubernamentales. Este 
patrón no sólo se verificó en el campo de las políticas monetaria y de cambio, sino también en otras áreas, incluyendo las políticas industrial y de comercio exterior. En este último caso, autores que estudiaron la formulación de la política de comercio exterior durante el gobierno de Fernando Henrique Cardoso, resaltaron el alto grado de autonomía burocrática en la toma de decisiones, tales como la legislación antidumping, la definición de subsidios, derechos compensatorios y salvaguardias, entre otras, elaboradas de forma independiente y sin transparencia por las elites burocráticas (Lima y Santos, 2001; Carvalho, 2000).

Un segundo conjunto de factores se refiere al grado de homogeneidad de las ideas compartidas por el núcleo duro del Estado, al grado de radicalismo o de moderación que las elites estatales imprimen a las directrices liberales y la mayor o menor rigidez con que manipulan los instrumentos de política económica. Aspecto no menos relevante es la presencia o ausencia de un patrón unificado de acción por parte de estas elites. Con relación a los gobiernos anteriores, la Presidencia de Fernando Henrique se caracterizó por una mayor cohesión del equipo gubernamental. Además, el presidente gobernó con el auxilio de una amplia base de sustento parlamentario durante todo su primer mandato, contando con el apoyo de cerca del $74 \%$ en la Cámara de los Diputados y del $83 \%$ en el Senado.

Con el respaldo de una alianza que reunió un amplio abanico partidario, se configuró un gobierno de coalición de centro-derecha, disponiendo de un poder ampliamente mayoritario. Tal soporte parlamentario, aunque de difícil administración, garantizó al gobierno la aprobación de importantes puntos de su agenda. En este aspecto, destacan las reformas constitucionales indispensables para profundizar el corte con el pasado y cumplir la meta de destruir el legado de la era Vargas, principalmente en lo tocante al orden económico, respecto al régimen del monopolio estatal de los recursos minerales e hídricos, así como la distinción entre empresas nacionales y extranjeras, en términos de control de actividades económicas y acceso a las fuentes de crédito oficial. Además se iniciaron las reformas en las áreas laboral, de seguridad social y administrativa. Finalmente, el Legislativo fue el escenario de articulaciones que desembocaron en la aprobación de medidas fundamentales de la agenda gubernamental. De esta forma, pasaron por el Congreso todo un conjunto de leyes necesarias para la operación del nuevo modelo económico. Entre éstas, cabe destacar el cambio de la Ley de Puertos y de Patentes, y la elaboración de la nueva legislación referente a las concesiones de servicios públicos, entre otras.

En esta línea de reflexión, la primacía decisoria de la alta tecnocracia y la relevancia del Congreso no pueden ser tratadas como aspectos antagónicos de la dinámica gubernamental. Al contrario, las interconexiones entre el foro burocrático y parlamentario se tradujeron en acciones de conflicto y de cooperación, con un saldo favorable para el Ejecutivo. Efectivamente, cupo a la instancia congresual un papel crucial en la implementación de las propuestas del gobierno. Restaría aún al Legislativo funcionar como instancia ratificadora de los actos del Ejecutivo. Finalmente, representó el foro por excelencia para la gestión de conflictos, ya que los diferentes grupos de interés tenderían crecientemente a canalizar sus demandas a través de la instancia parlamentaria. A pesar 
del presidente y sus ministros haber insistido sistemáticamente en la versión de que gobernaban contra el Congreso, culpando a este poder por el atraso en la votación de las reformas, en verdad Ejecutivo y Legislativo desempeñaron funciones complementarias, siendo su forma particular de interacción y de negociación parte constitutiva del estilo de gestión del gobierno. En este sentido, el patrón clientelista no puede ser considerado como un rasgo afecto exclusivamente al Congreso, sino que hace parte de la lógica de actuación del gobierno como un todo.

La alta discrecionalidad de la autoridad presidencial y el amplio poder de decreto de que disfrutó el presidente entre 1995-20019 , constituyen la otra cara del control y de la cooptación de los partidos y de los parlamentarios por el jefe del poder ejecutivo durante el periodo considerado. El éxito del gobierno se basó, en gran parte, en el recurso generalizado a las prácticas clientelistas para asegurar la cohesión de la base partidaria del gobierno, en momentos de mayor conflicto y obtener la mayoría absoluta para aprobar las reformas económicas y, posteriormente, para garantizar la continuidad de la agenda pública mediante la aprobación de la reforma constitucional que permitiría la reelección presidencial. El reparto de los principales cargos de la Administración pública, fundamental para el intercambio político, contribuiría a su vez al deterioro de la capacidad de implementación de las políticas gubernamentales. La creación de las llamadas islas de excelencia por el fortalecimiento aún mayor del aislamiento burocrático, buscando ampliar los grados de autonomía del Ejecutivo y separando al llamado núcleo duro del Estado de las presiones externas, reproduciría los elementos centrales de este sistema, en un proceso de retroalimentación.

Finalmente, en lo tocante a las relaciones entre los sectores público y privado, desde el inicio de los años 90, con la llegada de Fernando Collor a la Presidencia, se viene produciendo el desmantelamiento de los foros corporativos de negociación empresario-Estado en el interior de la burocracia pública. De este modo, se observó la extinción progresiva de órganos como el CIP (Consejo Interministerial de Precios), el CDI (Consejo de Desarrollo Industrial), la CPA (Comisión de Política Aduanera), la CACEX (Cartera de Comercio Exterior) y el CONCEX (Consejo de Comercio Exterior), en el ámbito de las políticas industrial y comercial. Durante el gobierno de Fernando Henrique, fueron eliminados los últimos canales institucionalizados de negociación aún existentes en el seno de la burocracia gubernamental, rompiéndose con una de las marcas del antiguo modelo corporativo. Comisiones y Consejos económicos, integrados por agentes técnicos y liderazgos empresariales, desaparecerían como miembros del cuadro de agencias sectoriales de naturaleza consultiva o deliberativa. En el ámbito de la política macroeconómica, entre 1990 y 1994, el CMN (Consejo Monetario Nacional) vio sus integrantes reducidos de 17 a 3 miembros, reforzando su perfil técnico. Se eliminó también, como fue resaltado, el espacio de actuación de las Cámaras Sectoriales, que funcionaron entre los gobiernos Collor e Itamar Franco en la

9. Es preciso recordar que fue solamente al final del segundo mandato del presidente Fernando Henrique Cardoso que se aprobó el proyecto que regularía el uso de las Medidas Provisionales (Enmienda Constitucional 32/2001 - 12/09/01). 
negociación de acuerdos tripartitos en torno de políticas enfocadas a enfrentar problemas que afectaban a ciertas cadenas productivas, como las cadenas de la industria automovilística, la de la construcción naval, y la de la confección, entre otras, sometidas al impacto de las oscilaciones del mercado internacional y al aumento de la competencia de los productos importados. De esta forma, en la década de los 90, el desmantelamiento de las bases institucionales del Estado desarrollista contribuyó a reforzar el agotamiento del antiguo modelo. Desde la década anterior, el Estado desarrollista y las coligaciones sociopolíticas que le dieron sustento venían siendo sacudidas por los efectos de las transformaciones en el orden internacional. En los años 90, este tipo de Estado se desestructura como resultado de una acción deliberada del gobierno, que elimina sus soportes institucionales, como el aparato proteccionista y las referidas instancias de negociación, observándose una drástica reducción del Estado-empresario y la radicalización de la apertura externa de la economía, privilegiando una estrategia de atracción del capital internacional.

Sin embargo, cabe destacar que el aislamiento burocrático no implicó la interrupción de las líneas de comunicación entre el empresariado y la burocracia gubernamental a lo largo del periodo considerado. Durante la gestión de Fernando Henrique Cardoso, se observó incluso un fuerte intercambio e intensa comunicación entre líderes empresariales y autoridades gubernamentales, aunque bajo la forma de contactos de carácter más personal que institucional. Además, con cierta frecuencia, algunos ministros comparecieron ante entidades de peso como la FIESP y la CNI para debatir puntos de la agenda pública de interés del empresariado. Algunas agencias gubernamentales promovieron audiencias públicas para escuchar la opinión de empresarios sobre determinadas políticas. Finalmente, en ciertos organismos del gobierno federal, está prevista la presencia de representantes del sector privado industrial, a través de la CNI. Es el caso, por ejemplo, del Consejo Tutor del Fondo de Desarrollo Social del BNDES, del Consejo Nacional de Recursos Hídricos, del Consejo Tutor del Fondo de Garantía por Tiempo de Servicio (FGTS), del Consejo Deliberativo del Fondo de Amparo al Trabajador (CODEFAT), y de varios Consejos de Contribuyentes del Ministerio de Hacienda, siendo entre uno y tres el número de representantes admitidos. Así y todo, se trata de una participación contenida en un espacio específico y lateral, fuera de las instancias en las que se toman las decisiones estratégicas responsables de la definición de las líneas maestras de la política gubernamental.

Esta estrategia de reforma del Estado se manifiesta también con la creación de las agencias reguladoras, encargadas de la regulación de los sectores de infraestructura privatizados, principalmente en las áreas de telecomunicaciones (ANATEL), energía (ANEEL) y petróleo (ANP), agencias autónomas ligadas al Ejecutivo, que detentan el poder de definir las reglas de operación en las áreas de servicios públicos y en los sectores transferidos al control de la iniciativa privada. Desde su creación en 1997, se expandieron con celeridad, alcanzando nuevos campos de actividad, no sólo en la esfera del gobierno federal, sino también en la instancia regional. Dotadas de amplias prerrogativas, mantienen una tenue comunicación con el poder legislativo, quien detenta poca capacidad de ingerencia en sus actividades. Por otro lado, estas agencias se convierten 
en el blanco preferido de la acción de los grupos empresariales que buscan un espacio para la defensa de sus intereses frente al poder público.

Resumiendo las tendencias arriba señaladas, debe destacarse que tanto la alta tecnocracia aislada en la burocracia, como la amplia y heterogénea coalición parlamentaria de soporte del gobierno fueron cruciales en la implementación del programa gubernamental. Éste dependía fuertemente de la aprobación de las reformas constitucionales para alcanzar sus objetivos. Para eso, el presidente disponía tanto de una amplia base de apoyo, como de una distribución interna del poder que favorecía a los líderes de los partidos y las presidencias de la Cámara y del Senado, garantizando al Ejecutivo un alto control sobre el Congreso (Figueiredo y Limongi, 1999). De esta forma, se observó una actuación complementaria entre las dos instancias del poder.

\section{EMPRESARIADO Y PODER PÚBLICO EN LOS AÑOS 90}

En lo que se refiere al sector privado, la eliminación de los foros corporativos de negociación, sin la creación de un patrón alternativo que sustituyese el formato anterior, a través de canales institucionalizados de articulación con la burocracia estatal, induciría a la clase empresarial a un estilo particularista y defensivo de actuación en sus relaciones con el poder ejecutivo. Junto a la persistencia del patrón de acceso individual, estos rasgos contribuyeron a reforzar la segmentación históricamente sedimentada. Además, con el cierre del proceso decisorio, apenas un círculo restringido tendría condiciones de acceder y participar de las redes de conexiones con las altas esferas gubernamentales.

Por otro lado, en contraste con el periodo marcado por la industrialización sustitutiva, en el que el Ejecutivo constituía el espacio privilegiado de intercambio con los grupos privados, a partir de los años 80 , se observó un significativo traslado de la acción de los intereses organizados del Ejecutivo hacia el Legislativo, mediante la difusión de la práctica del lobby, que ya venía ganando relevancia desde el periodo de elaboración de la Constitución de 1988. En el transcurso de la década de los 90, se refuerza la tendencia a la valorización del Legislativo como espacio de interlocución y como locus legítimo para el ejercicio de la influencia y del poder de negociación de los grupos empresariales. La posición central alcanzada por el foro congresual se revela a través de innumerables iniciativas del empresariado en el sentido de modernizar y adaptar su estructura de representación de intereses a los cambios del perfil institucional del país. Movimientos importantes como la Acción Empresarial, diversas entidades de clase como la CNI, la FIESP, o la ABDIB, entre otras, volvieron sus actividades hacia el Congreso, con lo cual pasaron a mantener un permanente intercambio, acompañando la tramitación de los proyectos de interés para el sector empresarial. Dentro de esta línea de evolución, algunos factores merecen ser destacados ${ }^{10}$.

10. El análisis de estos cambios se basa en los datos obtenidos por el proyecto coordinado por la autora y por Renato BoSCHI, «Globalização, Elites Empresariais e Reconfiguração do Setor Privado 
El primero está representado por la creación de la Acción Empresarial en 1991, para acompañar en el Congreso la tramitación de la Ley de Modernización de los Puertos. Privada de una organización formal, la Acción Empresarial se caracterizó desde el inicio como un movimiento dotado de alto grado de flexibilidad y de libertad de acción, englobando un amplio abanico de intereses, actuando en momentos estratégicos en defensa de aspectos generales de la pauta empresarial. Además de en la nueva legislación portuaria, actuó intensamente durante la revisión constitucional de 1995 y, más recientemente, viene concentrando su actividad en torno a la tramitación de la reforma tributaria en el Congreso. Mantiene una estrecha conexión con la CNI y con el IBS (Instituto Brasileño de Siderurgia), que le suministran soporte organizacional, además de tener también vínculos con un número extremamente amplio de organizaciones empresariales, lo que le da un gran poder de movilización. En la evaluación de los liderazgos empresariales, se trata de una experiencia exitosa, que representa una novedad en la trayectoria de la estructura de representación de intereses del empresariado brasileño, en la medida en que su meta es la defensa de intereses de carácter englobador, que afectan al conjunto del empresariado (Diniz y Boschi, 2001).

Otra innovación asociada a la posición central de la actividad parlamentaria fue la creación de la COAL (Coordinadora de Asuntos Legislativos), en el ámbito de la CNI. Se trata de una asesoría para asuntos legislativos que tiene como objeto el acompañamiento de los trabajos legislativos de interés para el empresariado industrial, suministrando informaciones a las diferentes entidades de clase sobre los principales proyectos y, al mismo tiempo, encaminando a los parlamentarios no tan sólo datos, sino sugerencias formuladas por las organizaciones empresariales. Desde hace cinco años la COAL edita y circula en los medios empresariales la Agenda Legislativa, divulgando informaciones sobre los varios proyectos en tramite, explicitando la posición de las entidades de clase y sus principales propuestas.

La creación de la COAL no es el único resultado del esfuerzo modernizador que está alterando la forma de actuación de la CNI. Durante la última década, la tradicional entidad de cúpula del empresariado industrial pasó por una revitalización que, si bien no puede ser entendida como una transformación radical, le permitió alcanzar mayor dinamismo y representatividad. Uno de los cambios consistió en la reestructuración y ampliación de sus consejos temáticos, que pasaron a formular propuestas para diferentes áreas, tales como política industrial, desarrollo tecnológico, relaciones laborales, integración internacional, comercio exterior, medio ambiente y asuntos legislativos. Hubo también una importante transformación en la composición de estos consejos, que pasaron a incorporar, al lado de las organizaciones corporativas, las asociaciones sectoriales nacionales, como la ABDIB, la ABIQUIM, la ABINEE, o la ANFAVEA, entre otras. Otro aspecto de la modernización de la CNI fue la expansión y el perfeccionamiento de sus cuadros técnicos, así como el refuerzo de sus funciones de

no Brasil dos Anos 90», projeto Cientistas do Nosso Estado, FAPERJ/IUPERJ, 2000/2001. Véase principalmente Diniz y BosCHI (2001). Agradezco a Renato Boschi la discusión de una serie de puntos de la argumentación aquí desarrollada sobre la estructura de representación de los intereses en Brasil. 
asesoría en diferentes campos, inclusive en el acompañamiento de los trabajos del Congreso, además de la producción y divulgación de informaciones relevantes sobre las cuestiones económicas y políticas de interés para sus asociados. A través de su departamento de investigaciones, pasó a promover estudios para evaluar el impacto de las políticas gubernamentales sobre los diferentes sectores industriales, realizando consultas sistemáticas sobre las opiniones de los empresarios acerca de los rumbos de la economía y otros asuntos de la pauta empresarial.

Un tercer hecho indicativo del proceso de adaptación de las organizaciones empresariales al nuevo contexto fue la creación de la ONIP (Organización Nacional de la Industria del Petróleo). Caracterizada como una organización no gubernamental de carácter movilizador, la ONIP reúne los intereses de la cadena productiva del petróleo en operación en el país. Se propone actuar como un espacio de articulación y de cooperación envolviendo a los principales actores, la Petrobras, las empresas privadas, entidades de clase y órganos gubernamentales, en la búsqueda de estrategias comunes para la expansión y el fortalecimiento de la cadena productiva como un todo. En otras palabras, se intenta llegar a un consenso en torno de intereses comunes, más allá de las diferencias sectoriales. Al contrario de las organizaciones anteriores, el blanco de la actuación de la ONIP es el poder ejecutivo, destacándose la ANP (Agencia Nacional del Petróleo), el Banco Central, el BNDES, los ministerios de Hacienda, Ciencia y Tecnología, Desarrollo y otros. Entre las entidades de clase, están incluidos sindicatos y federaciones patronales, integrantes de la estructura corporativa, junto a asociaciones sectoriales nacionales ligadas a la cadena del petróleo. Reforzando la argumentación anteriormente desarrollada, la articulación con el gobierno se da a través del montaje de una red de conexiones envolviendo a los diferentes actores, según un patrón informal, no existiendo canales y foros institucionalizados de negociación y de acceso.

Por último cabe detectar también un esfuerzo adaptativo frente a los efectos de la globalización y de la internacionalización de la economía que afectaron a la estructura productiva del país en la última década. En el seno del empresariado se observa la ascensión de una perspectiva internacionalista, ganando espacio en relación con la visión nacionalista del pasado. Esta postura tiene repercusiones en el ámbito de las asociaciones sectoriales paralelas, donde ya se puede detectar un proceso de adaptación a las imposiciones del nuevo patrón de inserción externa. Un ejemplo paradigmático es el de la ABDIB que alteró sus estatutos para incluir, entre sus socios, empresas extranjeras y admitir, en sus cuadros dirigentes, ejecutivos de empresas multinacionales, práctica inexistente durante la vigencia del modelo anterior. Habiéndose destacado en el pasado como líderes de la antigua estrategia de desarrollo, los industriales de este sector fueron alcanzados por la retracción del Estado y la crisis de las finanzas públicas. Como reacción redireccionaron sus inversiones, aprovechando las oportunidades surgidas con las concesiones de obras en las áreas de infraestructura, asociados al capital externo. Cambiando el nombre por el de Asociación Brasileña de la Infraestructura y de la Industria de Base, la entidad, otrora reducto de grupos de orientación nacionalista, como Cláudio Bardella y Paulo Villares, hoy abriga también grupos europeos y norteamericanos, como la Shell y la Exxon, la argentina YPF o la Asea Brown Boberi. 
Estos grupos poseen una posición privilegiada en el mercado internacional, representando para sus socios brasileños amplias oportunidades de expandir sus negocios o simplemente permanecer en el mercado. Éste no es un ejemplo aislado, observándose en otras organizaciones empresariales cambios semejantes de apertura a los grupos e intereses extranjeros.

\section{CONSIDERACIONES FINALES}

Como fue destacado a lo largo de este trabajo, la década de los 90 representó efectivamente un corte con relación a la estrategia desarrollista del pasado reciente, no sólo en sus aspectos económicos, sino también en lo que se refiere a los fundamentos institucionales y los soportes político-ideológicos del antiguo modelo. He aquí el porqué los contrastes entre los años 80 y 90 son más relevantes que los puntos de continuidad.

Entre las rupturas más significativas es posible mencionar, en primer lugar, las que se refieren a las prioridades de la agenda pública. Mientras en los años 80 la agenda pública estaría comprometida básicamente con las reformas políticas para restaurar la democracia y eliminar la herencia autoritaria, en la década de los 90, las prioridades serían la estabilización económica y las reformas orientadas al mercado, fundamentalmente la privatización y la apertura de la economía.

Un segundo aspecto se refiere a la amplitud de la agenda. En los años 80, es notorio el extenso grado de alcance de la agenda pública, incluyendo, además de los puntos de la reforma política, la preocupación por el agravamiento de la inflación y la deuda externa, junto al énfasis en las políticas sociales. En contraste, en la década de los 90 la agenda se vuelve rígida en torno a las metas de estabilización y de ajuste fiscal. Equilibrio presupuestario, recorte de gastos, saneamiento económico y financiero, prioridad de las metas de austeridad fiscal, atracción de capitales externos son las nuevas directrices, caracterizando una agenda minimalista, en la cual no habría espacio para políticas de crecimiento económico y aumento de las oportunidades de empleo.

Considerando las características de la coalición dominante y del núcleo dirigente, hasta el final de los años 80 , se verificó un alto grado de disentimiento entre las elites dirigentes, inclusive respecto a las directrices que deberían nortear los rumbos del capitalismo brasileño. Nacionalismo-internacionalismo, liberalismo-intervencionismo, Estado-mercado eran algunas de las dicotomías alrededor de las cuales se alineaban diferentes posiciones, con distintos matices. Prevalecía, en fin, un amplio desacuerdo respecto al agotamiento del antiguo modelo, ya fuera en sus fundamentos económicos, ya en sus soportes institucionales, ya que había todavía una apuesta en sus potencialidades. En contraposición, en los 90, la meta del desmantelamiento del legado del pasado se vuelve preponderante con la ascensión de Fernando Collor a la Presidencia de la República, declarándose la guerra al capitalismo autárquico brasileño, que sería asociado a las distorsiones de un patrón de industrialización artificial, poco eficiente y poco competitivo. A partir de entonces, se inician las políticas que realizarán la fractura con el antiguo orden, bajo la égida de las directrices neoliberales consagradas internacionalmente. Este 
corte se radicaliza con la elección en 1994 del presidente Fernando Henrique Cardoso al frente de una amplia coalición de centro-derecha, incluyendo un abanico diversificado de partidos políticos, entre los cuales están los tres mayores, PSDB, PFL y PMDB ${ }^{11}$. Se redefine drásticamente la agenda pública, cuya prioridad, además de la estabilización económica promovida por el Real, será la ejecución de las reformas económicas encaminadas al mercado, al lado de las reformas constitucionales. La ruptura con el pasado alcanzará a las diferentes dimensiones del antiguo modelo: sus fundamentos económicos, institucionales e ideológicos.

La implementación de esta agenda se dará en dos frentes, respectivamente, la instancia burocrática, formada por la alta tecnocracia aislada, responsable de las decisiones estratégicas en el área de la política macroeconómica y el foro parlamentario, escenario de las reformas constitucionales y de la elaboración de algunas de las leyes fundamentales para la operación del nuevo modelo centrado en el mercado y la apertura externa. En lo tocante a la alta burocracia, su estilo de acción se caracterizaría por el aislamiento burocrático y por el bajo grado de transparencia y de accountability. En esta instancia de poder, el acceso de actores externos, principalmente los sectores empresariales, asumiría predominantemente la forma de los contactos personales y vínculos informales. La permeabilidad a los intereses económicos no desaparecería, volviéndose apenas menos abierta y menos formalizada. La burocracia gubernamental persistiría siendo un espacio relevante para la presión de los intereses empresariales, sin embargo, aunque pueda alcanzar cierta intensidad de comunicación y de contactos, la articulación asume un formato no institucionalizado. Así, incluso en el caso de la cadena del petróleo, de gran peso económico y significación política, además del alto grado de organización resultante de la eficacia de la actuación de la ONIP, los vínculos se caracterizan por la informalidad. Este patrón no es residual, ocurriendo tanto en el ámbito de la burocracia más tradicional, como en sus segmentos más modernos, incluyendo las agencias reguladoras, expresión de la reciente experiencia del Estado para atender a la nueva realidad post-reformas.

En contrapartida, es en el Congreso donde confluye la participación de los intereses organizados. En este sentido, se observa un contraste en relación con el patrón histórico de los años 30 a 80, cuando el centro de gravedad de la acción empresarial se situaba en el Ejecutivo. En el contexto actual, el poder legislativo tiende a valorizarse crecientemente como espacio de interlocución, como locus legítimo para el ejercicio de la influencia de los grupos económicos sobre el poder público y como foro de negociación privilegiada. En este escenario, cabe destacar la reactivación de los lobbies como instrumento básico de presión de la clase empresarial. Dentro de esta línea de actuación, tal como fue destacado, un hecho nuevo fue la creación de la COAL, en el ámbito de la CNI, que tiene como blanco el Congreso y ejerce intensa actividad, acompañando los trabajos legislativos, divulgando informaciones sobre los proyectos de ley y articulando

11. Durante su primer mandato, la base de sustento parlamentario del presidente Fernando Henrique contó con el apoyo del PSDB, PMDB, PFL, PPR y PTB. En el segundo mandato el grupo de apoyo al gobierno contó con 4 partidos: el PSDB, el PMDB, el PFL y el PPB. 
alianzas alrededor de sus posiciones. Otras innumerables entidades de clase del empresariado mantienen despachos en Brasilia, siendo acreditadas por la primera Secretaría de la Cámara de los Diputados para acompañar la tramitación de los proyectos. En una línea de acción concertada, movilizando intereses más generales, se debe mencionar a Acción Empresarial, que tuvo una actuación bastante significativa en ocasión de la tramitación de la nueva Ley de Puertos y de la reforma tributaria, esta última todavía inconclusa. Además, reforzando una antigua tendencia, los empresarios mantienen una fuerte representación en el Congreso, principalmente en la Cámara de los Diputados donde, desde 1945, un número notable de diputados-empresarios tienen escaño. Aun sin constituir una facción, dotada de cierto grado de unidad, los representantes empresariales tienden a aglutinarse en función de intereses funcionales, regionales o sectoriales, desarrollando una actividad más intensa en las principales comisiones, sobre todo en aquellas donde son discutidos los proyectos directamente relacionados con sus intereses, en las áreas fiscal, laboral y tributaria, entre otras.

Finalmente, si consideramos la estructura de representación de intereses del empresariado industrial, se pueden detectar puntos de continuidad y de ruptura. En cuanto a los primeros, la estructura formal permanece privada de una organización de cúpula de alto grado de alcance que sea capaz de dar forma y expresión a los intereses multisectoriales. Por otro lado, por fuera de la estructura formal, como resultado del proceso adaptativo de la última década, surgieron nuevas organizaciones centradas en la articulación y movilización de sectores de la producción industrial o incluso del conjunto del empresariado, para la negociación frente al Ejecutivo o al Legislativo, con el objetivo de defender políticas de interés de la clase empresarial en su conjunto o de algunos de sus segmentos más significativos. Éste es, como ya fue visto, el caso de la ONIP, representando los intereses de la cadena productiva del petróleo y de la Acción Empresarial, movimiento integrado por más de 50 entidades empresariales para acompañar e influir en la aprobación de leyes que afectan al funcionamiento del mercado brasileño, como la nueva Ley de Puertos y de Patentes, así como la reforma tributaria. Se trata de iniciativas innovadoras que tienden a volver más dinámico el complejo organizacional del empresariado industrial. Representan la búsqueda de formas de acción capaces de contornear la heterogeneidad, las fragmentaciones y divisiones internas, movilizando intereses más generales y buscando articular formas concertadas de actuación.

De esta forma, retomando el argumento central de este trabajo, los años 90 representaron efectivamente una década de cambios, desencadenados por un conjunto de políticas enfocadas a la liberación de las fuerzas del mercado, fundamentalmente la privatización del patrimonio público, la apertura al exterior, el estrechamiento de los vínculos con el mercado internacional, además de las reformas constitucionales. Estos cambios llevaron a un profundo corte con el pasado, con impacto no desdeñable sobre la sociedad, la economía y el orden político. De esta manera, las alteraciones alcanzaron al modelo económico, el tipo de capitalismo, la modalidad de Estado, las formas de articulación Estado-sociedad y el régimen político. Se desestructura el llamado modelo del trípode, sustentado por el pacto desarrollista, representado por el énfasis en las empresas de capital nacional, estatal y extranjero, con la drástica reducción del sector 
estatal, el debilitamiento del segmento privado nacional y el fortalecimiento de la empresa extranjera, promoviéndose un acentuado proceso de desnacionalización de la economía. Bajo la influencia de las nuevas directrices pro-mercado, el mando del nuevo orden económico pasa a las grandes corporaciones transnacionales, cuya prioridad es la inserción-integración de las economías nacionales en una estructura de poder de visión transnacional, a la cual apenas una fracción muy restringida del empresariado local, en general asociada a los grandes conglomerados, tiene condiciones de acceder. Los demás segmentos, ocupando una posición marginal, viven en el límite de la supervivencia. Los que no perecieron, garantizaron su supervivencia por la fusión, asociación o colaboración con empresas líderes internacionales y, por tanto, tienen su suerte encadenada al éxito de la estrategia dominante. En este modelo pierde actualidad la separación entre empresa nacional -empresa extranjera y prevalece un concepto de empresa brasileña, caracterizada por ser aquella que está en el país, se instala en el país, invierte en el país, en él produce y en él crea empleos. En consonancia con esta misma lógica, pierde vigor la división centro - periferia, siendo sustituida por la idea de integración en un orden mundial globalizado, donde no habría espacio para el antiguo Estado-nación.

En este contexto, sobre todo en función de la desaceleración económica de los países hegemónicos, de la crisis de Argentina, del vaciado del Mercosur y de la perspectiva de adhesión al ALCA, algunas preguntas se imponen, entre las cuales, sí habrá espacio para definir una estrategia alternativa de desarrollo. Para conseguirlo, un camino posible sería la reestructuración de las relaciones de poder, teniendo en cuentan articular una nueva coalición capaz de sustentar otra vía de desarrollo caracterizada por un nuevo enfoque con relación a la empresa extranjera, al comercio exterior, a la política industrial, al desarrollo tecnológico, al crecimiento económico, al papel del mercado interno y a la urgente cuestión de la redistribución de la renta y reducción de la desigualdad. En este sentido, asume el primer plano la cuestión de cómo resolver el dilema entre un estilo de desarrollo más autónomo, pero sin embargo poco propicio al aumento de la competitividad, y un camino de búsqueda de la competitividad dentro de un modelo económico incompatible con el crecimiento y el desarrollo sostenido.

Aunque los cambios de los años 90 representaron un punto de inflexión en la trayectoria de la sociedad brasileña, problemas históricos de exclusión presentan un alto grado de persistencia. Efectivamente, las referidas transformaciones fueron eficaces en el desmantelamiento de los cimientos del antiguo orden, volviendo anacrónica cualquier perspectiva de regreso a la situación anterior, así como la utilización de antiguos paradigmas para la interpretación del momento presente. Por otro lado, las reformas y políticas gubernamentales no fueron eficientes para conducir el país a un nuevo apogeo de desarrollo, permitiendo apenas brotes espasmódicos de crecimiento.

Frente a este tipo de callejón sin salida, se acentúan las divisiones en el interior del empresariado industrial, aunque la corriente dominante apunte en el sentido de un refuerzo del actual modelo.

Esta tendencia, por otro lado, no debe oscurecer la percepción de las señales de un significativo cambio que viene ocurriendo, principalmente, tras la crisis externa de mediados de 1997. Se trata de la constitución de un núcleo, envolviendo entidades de peso, 
como la FIESP y el IEDI, liderazgos antiguos y nuevos, alrededor de una postura crítica ante lo que se configura como el punto frágil de las políticas liberales, la incapacidad de retomar el crecimiento y definir estrategias a largo plazo. La principal demanda es la redefinición de los rumbos del capitalismo brasileño mediante una forma de inserción externa compatible con la preservación y el fortalecimiento del parque industrial local, así como del patrimonio construido a lo largo de las varias fases de industrialización del país.

El objetivo es la formulación de una nueva estrategia que preserve el espacio para una política industrial consistente. En este sentido, se observa la confluencia en torno a una nueva visión, en conflicto con la perspectiva más ortodoxa hoy dominante, capaz de conducir las políticas de inserción en el sistema internacional de forma independiente, en beneficio de un proyecto para el desarrollo del país. Para ganar fuerza política, esta postura necesita trascender los estrechos límites del sector empresarial, ensanchando el abanico de alianzas. La incorporación de otros segmentos, incluyendo aquí los liderazgos sindicales, encuentra, sin embargo, un obstáculo que no puede ser subestimado, pues al final de cuentas, implica romper con la histórica inflexibilidad del empresariado brasileño ante la pauta de demandas de los trabajadores. Como ya fue destacado, la falta de tradición de pactos y negociaciones, incluyendo la disposición para transigir y ceder, en beneficio de una agenda común es un rasgo del desarrollo histórico de la clase empresarial. Éste es sin duda uno de los principales desafíos a los que se enfrenta el empresariado en el presente momento.

\section{BIBLIOGRAFÍA}

Arbix, G. A Câmara Banida. En Arbix, G. y Zilbovicius, M. (org.). De JK a FHC: A Reinvenção dos Carros. São Paulo: Ed. Escritta, 1997.

- Guerra Fiscal e Competição Intermunicipal por Novos Investimentos no Setor Automotivo Brasileiro. Dados, 2000, vol. 43, n 1.

Boschi, R. R. Elites Industriais e Democracia. Rio de Janeiro: Graal, 1979.

- A Arte da Associação, Política de Base e Democracia no Brasil. São Paulo/Rio de Janeiro: Vértice/IUPERJ, 1987.

Boschi, R. R.; Diniz, E. y Santos, F. Elites Políticas e Econômicas no Brasil Contemporâneo. São Paulo: Konrad-Adenauer-Stiftung, 2000.

Cardoso, A. M. Sindicatos, Trabalhadores e a Coqueluche Neoliberal. A Era Vargas Acabou? Rio de Janeiro: FGV, 1999.

- A Trama da Modernidade: Pragmatismo Sindical e Democratização no Brasil. São Paulo: DIFEL, 1999.

Carvalho, M. I. V. de. O Processo de Formulação da Agenda: Brasil e Estados Unidos na Rodada do Milênio da OMC. Paper apresentado durante o XXIV Encontro anual da ANPOCS. Petrópolis. 23-27 de outubro, 2000, 20 pp.

Castro Santos, M. H. de. Política e Políticas de Uma Energia Alternativa: O Caso do Proálcool. Rio de Janeiro: Editora Notrya/ANPOCS, 1993.

Cohen, J. y Rogers, J. (eds.). Associations and Democracy. London/New York: Verso, 1995. 
Cohen, J. Democracy and Liberty. En Elster, J. (ed.). Deliberative Democracy. Cambridge, New York: Cambridge University Press, 1998.

Conaghan, C. y Malloy, J. Unsettling Statecraft, Democracy and Neoliberalism in Central Andes. Pittsburgh: University of Pittsburgh Press, 1994.

Costa, V. R. A Armadilha do Leviatã: A Construção do Corporativismo no Brasil. Rio de Janeiro: Editora UERJ, 1999.

De NegRi, J. A. Avaliação do Regime Automotivo Brasileiro. Ipea, mimeo, 1998, 45 pp.

Delgado, I. G. Previdência Social e Mercado no Brasil. São Paulo: Editora LTR, 2001.

Diniz, E. Reformas Econômicas e Democracia no Brasil dos Anos 90: as Câmaras Setoriais como Fórum de Negociação. Dados, 1994, vol. 37, nº 2.

- Governabilidade, governance e reforma do Estado: considerações sobre o novo paradigma. Revista do Serviço Público, 1996, Ano 47, vol. 120, n² 2, maio-agosto.

- Crise, Reforma do Estado e Governabilidade. Rio de Janeiro: Fundação Getúlio Vargas, 1997.

- Uma Perspectiva Analítica para a Reforma do Estado. Lua Nova, 1998, nº 45.

- Globalização, Reformas Econômicas e Elites Empresariais, Brasil Anos 2000. Rio de Janeiro: Editora FGV, 2000.

DinIz, E. y BosCHI, R. R. Autonomia e Dependência na Representação dos Interesses Industriais. Dados, $1979, \mathrm{n}^{\circ} 22$.

- Empresários e Constituinte: Continuidades e Rupturas no modelo de desenvolvimento capitalista no Brasil. En CAmargo, A. y Diniz, E. (orgs.). Continuidade e Mudança no Brasil da Nova República. São Paulo/Rio de Janeiro: Vértice/IUPERJ, 1989.

- O Corporativismo na Construção do Espaço Público. En BosCHI, R. (org.). Corporativismo e Desigualdade: A Construção do Espaço Público no Brasil. Rio de Janeiro: Rio Fundo/IUPERJ, 1991.

- Brasil: Um Novo Empresariado? Balanço de Tendências Recentes. En Diniz, E. (org.). Empresários e Modernização Econômica: Brasil, Anos 90. Florianópolis: UFSC/Idacon, 1993 a.

- Lideranças Empresariais e Problemas da Estratégia liberal no Brasil. Revista Brasileira de Ciências Sociais, 1993b, n ${ }^{\circ} 23$, ano 8.

- Estabilização e Reformas Econômicas no Brasil: A Visão das Elites Empresariais e Sindicais. Teoria e Sociedade, 1997, n 1. UFMG.

- Globalização, herança corporativa e a representação dos interesses empresariais: novas configurações no cenário pós-reformas. En BosCHI, R.; Diniz, E. y SANTOS, F. Elites Políticas e Econômicas no Brasil Contemporâneo. São Paulo: Fundação Konrad-Adenauer, 2000.

- Reconfiguração do Mundo Empresarial: Associações de Representação de Interesses, Lideranças e Ação Política. XXV Encontro Anual da ANPOCS, 16-20 de novembro, Caxambu, 2001.

Figueiredo, A. C. y Limongi, F. Poderes Legislativos e o Poder do Congresso. Monitor Público, 1995 , ano $2, \mathrm{n}^{\circ} 5$.

Franco, G. H. B. Alternativas de Estabilização: Gradualismo, Dolarização e Populismo. Revista de Economia Política, 1993a, vol. 13, nº 2, abril-junho.

- A Volta do Modelo Concentrador. Folha de São Paulo, 1993b, 20/05.

Hollingsworth, J. R.; SChmitter, P. y Streeck, W. Governing Capitalist Economies: Performance and Control of Economic Sectors. New York: Oxford University Press, 1994.

Leopoldi, M. A. P. Industrial Associations and Politics in Contemporary Brazil. St. Anthony's College, tesis de doctorado, 1984.

- Burocracia, Empresariado e Arenas Decisórias Estratégicas: Trajetórias do Neocorporativismo no Brasil (1939 a 1955). En Ciências Sociais Hoje. Rio de Janeiro: Rio Fundo/ANPOCS, 1992. 
Lima, M. R. S. y Santos, F. O Congresso e a Política de Comércio Exterior. Lua Nova, 2001, $\mathrm{n}^{\circ}$ 52, pp. 121-149.

LOCKE, R. Remaking the Italian Economy. New York: Cornell University Press, 1995.

Mann, M. The Autonomous Power of the State: Its Origens, Mechanisms and Results. En HaLL, J. (ed.). States in History. Oxford: Basil Blackwell, 1986.

Rua, M. G. y Aguiar, A. T. A Política Industrial no Brasil, 1985-1992: Políticos, Burocratas e Interesses Organizados no Processo de Policy-making. Planejamento e Políticas Públicas, jun/dez., 1995.

Santos, W. G. dos. A Pós-«Revolução» Brasileira. En Jaguaribe, H. (org.). Brasil, Sociedade Democrática. Rio de Janeiro: José Olympio, 1985.

TÁpIA, J. R. B. A Trajetória da Política de Informática Brasileira (1977-1991): atores, instituições e estratégias. Campinas, São Paulo: Editora da Universidade de Campinas, 1995

World Bank. Governance: The World Bank's Experience. Washington: The World Bank, 1994. 